\begin{tabular}{l|c|c}
\hline \multirow{2}{*}{$\begin{array}{l}\text { EREM 76/2 } \\
\text { Journal of Environmental Research, } \\
\text { Engineering and Management } \\
\text { Vol. 76/ No. 2/ 2020 } \\
\text { p. 43-53 } \\
\text { Dol 10.5755/j01.erem.76.2.21854 }\end{array}$} & \multicolumn{2}{|c}{ Biochar Effect on Nutrients Availability to Barley } \\
\cline { 2 - 3 } & Received 2018/10 & Accepted after revision 2020/06 \\
\cline { 2 - 3 } & Cross & http://dx.doi.org/10.5755/j01.erem.76.2.21854 \\
\hline
\end{tabular}

\title{
Biochar Effect on Nutrients Availability to Barley
}

\section{Irina Mukhina*, Elena Rizhiya}

Department of Soil Physics, Physic-Chemistry and Biophysics, Agrophysical Research Institute, 195220, Grazhdanskiy pr., 14, Saint Petersburg, Russia

\section{Tatiana Bankina}

Department of Agrochemistry, Biological faculty, Saint Petersburg State University, 199034, Universitetskaya Emb., 7-9, Saint Petersburg, Russia

*Corresponding author: muhinairina1989@gmail.com

Biochar can serve as a soil ameliorant preventing nutrient leaching. Due to its porous structure and chemical composition, it can also adsorb elements on its surface. However, various biochars have different sorption ability, and the mechanistic understanding of nutrient storage in biochar is missing. It is not clear if nutrients adsorbed by biochar will be available for plants. Therefore, it is necessary to investigate biochar efficacy in pure substrates to characterise its specific influence on plants. In this study, the sorption capacity and ability of the wood-based biochar to provide barley plants with nutrients was investigated. The sorption capacity of biochar was investigated by saturating it with Gelrigel nutrient solution. Then nutrient-enriched biochar was tested for its effect on barley growth in comparison with non-enriched biochar. The results of the sorption experiment showed that the wood-based biochar could adsorb high amounts of nutrients such as ammonium $\left(\mathrm{NH}_{4}^{+}\right)$, potassium, calcium and phosphate $\left(\mathrm{PO}_{4}{ }^{3-}\right)$, but not nitrate $\left(\mathrm{NO}_{3}{ }^{-}\right)$. Nutrient-enriched biochar showed an ability to support $46 \%$ higher dry biomass of barley than non-enriched biochar. These results suggest a potential of nutrient-enriched biochar for recovering essential nutrients for plants.

Keywords: nutrient-enriched biochar, sorption, barley, ammonium, nitrate, phosphate.

\section{Introduction}

Growing rates of mineral fertiliser production and application to agricultural soils lead to harmful effects to the environment. Production of mineral fertilisers causes air pollution with aerosols and greenhouse gases, contamination of soils and water bodies with heavy metals. Meanwhile, the use of these fertilisers in agriculture also has tremendous negative effects such as soil acidification, heavy metal pollution, and 
increased greenhouse gas (GHG) emissions from soil (Laird et al., 2010; Savci, 2012). Moreover, approximately $2-10 \%$ of nutrients from mineral fertilisers leach from the soil to water bodies causing eutrophication (Savci, 2012). Losses of nutrients through leaching and GHG emissions considerably decrease the efficiency of mineral fertilisers. Improving of nutrient use efficiency is required to decrease production and use of fertilisers. Researchers propose amendment of soils with biochar as a solution to retain nutrients and decrease their leaching from agricultural soils.

Biochar is produced by pyrolysis of organic waste (residues from agriculture and forestry, sewage sludge, etc.) and is characterised by a high content of stable carbon (C) compounds. Its application to soil as an amendment leads to carbon sequestration (Lehmann, 2007) and thus can help to decrease carbon dioxide $\left(\mathrm{CO}_{2)}\right.$ concentration in the atmosphere. Biochar amendment enhances such soil properties as soil aeration, aggregation, $\mathrm{pH}$, cation-exchange capacity, water-holding capacity and availability of nutrients to plants (Van Zwieten et al., 2009; Major et al., 2010; Glaser et al., 2002; Lehmann et al., 2003). All these properties will modulate changes in activity, abundance and diversity of microbiota as well as plant growth (Rondon et al., 2007). But there is still no consensus on the net absolute benefits of applying pure biochar for nutrient recovery. The reason is that pure biochar addition to soils does not always give consistent yield increases, and the plant responses to biochar addition vary widely (Jeffery et al., 2011; Cornelissen et al., 2013; Bonanomi et al., 2017). Thereby, the improvements of crop production and plant growth may be dependent on the mechanisms behind the capture, and subsequent release of organic or inorganic mineral nutrients by different types of biochar. Biochar has the ability to adsorb cations, anions and non-polar organic compounds (Fujita et al., 1991; Sander and Pignatello, 2005), thereby reducing leaching of nutrients (mineral nitrogen: ammonium $\left(\mathrm{NH}_{4}^{+}\right)$and nitrate $\left(\mathrm{NO}_{3}^{-}\right)$; phosphates $\left(\mathrm{PO}_{4}{ }^{3-}\right)$ and others) from soils (Zhang et al., 2015; Shepherd et al., 2016). Moreno-Castilla (2004) determines pore texture, surface chemistry and mineral matter content as the main characteristics which influence carbon sorption capacity. Sorption capacity, porosity and other biochar physical properties vary with the pyrolysis temperature and the type of biomass used as raw material (Lehmann, 2007; Downie et al., 2009). Patra et al. (2016) distinguished the following mechanisms responsible for the sorption: precipitation, complexation, ion exchange, chemisorption, and physical sorption. The sorption capacity of biochar could lead to lower nutrient leaching from soils and higher nutrient use efficiency, thus, reducing the need in fertilisers (Gronwald et al., 2015).

However, the availability of the adsorbed nutrients for plants is uncertain and depends on soil type, feedstock for biochar production and pyrolysis conditions. Several studies have shown that nutrients retained by biochar slowly become available to plants as a result of decomposition of char and changes in soil properties (Spokas et al., 2012; Biederman and Harpole, 2013). Investigations of plant uptake of nutrients adsorbed by biochar are crucial for understanding of the biochar application effect on nutrient retention in soils and their availability to plants. Therefore, investigations of the amendment efficacy require the study of pure components to characterise their specific behaviour in soil. Thus, this study was aimed to analyse sorption ability of biochar and its influence on plant growth in pure sand.

It was hypothesised that biochar will adsorb a significant amount of nutrients from the nutrient solution, which will improve barley growth.

\section{Materials and methods}

\section{Materials}

The sorption ability of biochar was examined in a pure sand substrate using a modified Gelrigel mixture as a nutrient solution. Treatment with bidistilled water was chosen as a control as it was characterised by the absence of any dissolved components. The nutrient retention capacity of biochar was studied in the experiment. Comparison of biochar properties in bidistilled water and nutritive solution would help to understand how biochar elemental composition changes in bidistilled water and how nutrients are adsorbed by biochar from Gelrigel solution. Concentrations of 
the target nutrients $\left(\mathrm{NH}_{4}^{+}, \mathrm{NO}_{3}{ }^{-}, \mathrm{P}^{3+}\right.$, and $\left.\mathrm{K}^{+}\right)$and trace elements $\left(\mathrm{Ca}^{2+}\right.$, and $\left.\mathrm{Mg}^{2+}\right)$ in biochar were determined before and after the sorption period. Subsequently, the amounts of nutrients adsorbed onto biochar were calculated based on their initial and final concentrations in the solutions and the biochar.

The sand was chosen as a pure substrate for the experiment. Sand is commonly used as a substrate in hydroponics. Assimilation of nutrients by plants from solutions in sands is more favourable than in soils due to the fact that the distribution of nutrients in sand is more even than it can be in soils. Proper washing of the sand was conducted to remove any nutrients from it, thus avoiding influence of the substrate on the results of the experiment. The sand was placed in $20 \%-\mathrm{HCl}$ for $7-10$ days. Then it was washed with a large amount of water and placed into the acid again. This operation was repeated 4-5 times until hydrochloric acid became transparent. After that, the sand was washed with distilled water until its $\mathrm{pH}$ value became constant. As the final step, the sand was heated at $800^{\circ} \mathrm{C}$ for 24 hours.

Biochar was produced from wooden residues (birch, aspen, alder) by fast pyrolysis under the temperature of $550{ }^{\circ} \mathrm{C}$. Biochar obtained from wooden residues was chosen for the study since it is the main type of biochar produced in Russia. $\mathrm{C}, \mathrm{N}$ and $\mathrm{H}$ contents in biochar were determined using elemental analyser Leco CHN-628 (USA). Ammonium $\left(\mathrm{NH}^{4+}\right)$ was determined by the colorimetric method in the extraction of $2 \% \mathrm{KCl}$ with Nessler reagent $\left(\mathrm{K}_{2} \mathrm{Hg}_{14} \mathrm{KOH}\right)$ (Lenreactiv, Russia) (Arinushkina, 1970). Nitrates $\left(\mathrm{NO}_{3}{ }^{-}\right)$were determined in the aqueous extract by the disulfophenol method (Arinushkina, 1970). The method of Kirsanov was used to determine $\mathrm{P}$ and $\mathrm{K}$ concentrations ( 0.2 normal solution of $\mathrm{HCl}_{5} \mathrm{H}_{2} \mathrm{O}$ soil extract) (Arinushkina, 1970). Phosphorus was determined by the colorimetric method with the addition of the Truog 's reagent (0.002 normal solution of $\mathrm{H}_{2} \mathrm{SO}_{4}\left(\mathrm{NH}_{4}\right)_{2} \mathrm{SO}_{4}$ ) (Lenreactiv, Russia) and $\mathrm{SnCl}_{2}$ as a reducing agent (Arinushkina, 1970). The determination of potassium was carried out by a flame-photometric method (Arinushkina, 1970). The determination of $\mathrm{Ca}$ and $\mathrm{Mg}$ was carried out in an extract with ammonium acetate $\left(\mathrm{CH}_{3} \mathrm{COOHN}{ }_{4}\right)$ by the Schollenberger titrimetric method (Arinushkina,
1970). Heavy metals were determined using an atom absorption spectrometer (Shimadzu AA-300, Japan). Benzo[a]pyrene concentration in biochar was determined by HPLC (Lumachrome, Russia) after extraction with acetone-cyclohexane.

Porosity of biochar was determined using equation:

Porosity $=1-D b / D p$

Where: $D b$ is bulk density $\left(\mathrm{g} \mathrm{cm}^{-3)}\right.$;

$D p$ is specific bulk density $\left(\mathrm{g} \mathrm{cm}^{-3}\right)$.

Specific bulk density was determined using the pycnometer method (ASTM 9854 - 14). Bulk density was studied by EN ISO 60 (DIN 53468), by apparatus HLL Landgraf Laborsysteme (Germany). The bulk material was poured through a standardised funnel into a collecting vessel with a defined volume. By means of differential weighing, the mass bulk density was calculated.

In the laboratory experiment, barley (Hordeum distichon L.) was used to study the uptake of nutrients from biochar.

\section{Experiment 1: Nutrient sorption capacity of biochar}

For the experiment, biochar was ground with a mortar and pestle and 1-2-mm size fraction was used in the experiment. A modified aqueous mixture of Gelrigel (Prusakova et al., 2008), which is commonly recommended for sands in hydroponics and sandy soils, was used as a nutrient solution. All nutrients of the Gelrigel mixture were dissolved in 1 litre of bidistilled water to make an aqueous solution. Its composition is presented in Table 1. Using bidistilled water as a control to the nutrient solution allowed to analyse nutrient leaching from biochar in aqueous solutions.

Table 1. Composition of the Gelrigel nutrient solution

\begin{tabular}{c|c}
\hline \multicolumn{1}{c|}{ Component } & Value \\
\hline $\mathrm{Ca}\left(\mathrm{NO}_{3}\right)_{2}, \mathrm{~g} \mathrm{l}^{-1}$ & 0.49 \\
\hline $\mathrm{KCl}, \mathrm{g} \mathrm{l}^{-1}$ & 0.075 \\
\hline$\left(\mathrm{NH}_{4}\right)_{2} \mathrm{SO}_{4}, \mathrm{~g} \mathrm{l}^{-1}$ & 4 \\
\hline $\mathrm{KH}_{2} \mathrm{PO}_{4}, \mathrm{~g} \mathrm{l}^{-1}$ & 0.14 \\
\hline $\mathrm{MgSO}_{4} \cdot 7 \mathrm{H}_{2} \mathrm{O}, \mathrm{g} \mathrm{l}^{-1}$ & 0.12 \\
\hline
\end{tabular}


Concentrations of the investigated nutrients in the Gelrigel solution were calculated (Table 2).

Table 2. Concentration of nutrients in the Gelrigel solution

\begin{tabular}{c|c}
\hline Substance & Concentration \\
\hline $\mathrm{NO}_{3}^{-}, \mathrm{mg} \mathrm{kg}^{-1}$ & 294.0 \\
\hline $\mathrm{NH}_{4}^{+}, \mathrm{mg} \mathrm{kg}^{-1}$ & 1090.2 \\
\hline $\mathrm{P}, \mathrm{mg} \mathrm{kg}^{-1}$ & 31.9 \\
\hline $\mathrm{K}, \mathrm{mg} \mathrm{kg}^{-1}$ & 39.3 \\
\hline $\mathrm{Ca}, \mathrm{mg} \mathrm{kg}^{-1}$ & 196.0 \\
\hline $\mathrm{Mg}, \mathrm{mg} \mathrm{kg}^{-1}$ & 23.8 \\
\hline
\end{tabular}

Sand and biochar were placed in glass columns $5 \mathrm{~cm}$ in diameter and $10 \mathrm{~cm}$ high (Fig. 1). The columns were fastened together in the following order: the bottom tube was filled with sand, with $2-\mathrm{cm}$ layer of biochar on the top, and the upper tube was filled with sand. Filter paper was put between the layers of sand and biochar. The amount of biochar represented a 25 -tonnes ha ${ }^{-1}$ application rate or $10 \%$ of the total mass in the column. Such a high amendment rate was chosen to ensure that it would allow detecting any changes in the studied properties happening during the experiment.

The columns, 5 replicates for each treatment, were inserted in two containers: one with bidistilled water (BC) as a control, and another with nutritive solution (EB). The layer of the liquids was constantly maintained 5-mm deep during the experiment. Water and the nutrient solution filled the columns and reached the tops of the columns in 2 minutes after the columns were placed into the solutions. The columns were kept in the containers under laboratory temperature $18^{\circ} \mathrm{C}$ and relative air humidity approximately $60 \%$. The majority of research experiments have shown that biochars could have a highly variable water-holding capacity, depending on whether they are freshly made or were aged for some time, as it was in our experiment. Some biochars, especially those made of wood, are able to hold an amount of water more than 10 times of their own weight (Kinney et al., 2012). Moving water into small pores requires exceeding the capillary pressure of the narrowest part of the pore. Since capillary pressure is inversely proportional to the pore radius, it creates a soil water potential. The weight of the columns in water and the Gelrigel solution was measured until, on day 14 of the experiment, it became constant. After that, each layer was analysed for the content of nutrients.

Fig. 1. The sorption experiment with biochar

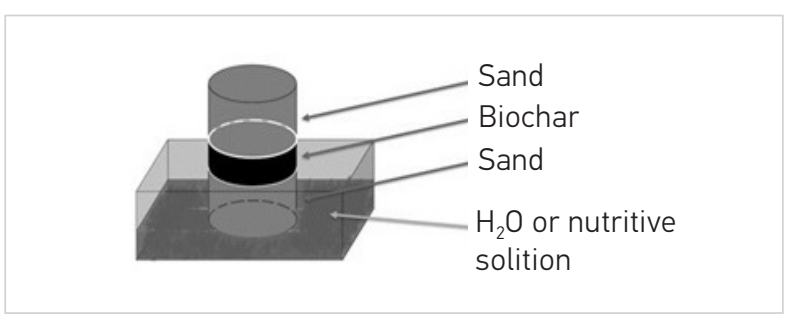

By the difference in the biochar nutrient concentration between $\mathrm{BC}$ and $\mathrm{EB}$ treatments, the amount of nutrients adsorbed by the biochar from the nutrient solution was calculated. The control treatment with water was necessary for the assessment of the biochar nutrient retention ability.

The coefficient of sorption intensity was determined as the ratio of concentration of the nutrient adsorbed by the biochar to concentration of the same nutrient in the solution.

\section{Experiment 2: Nutrient uptake from biochar}

$160 \mathrm{~g}$ of biochar saturated with bidistilled water or the Gelrigel solution (BC and EB, respectively) was introduced into the vessels with $0.5 \mathrm{~kg}$ of the sand. The sand-biochar mixture was moistured to reach 60\% of the field capacity (or $15 \%$ of soil water content). In each pot, 10 grains of barley were sown. The experiment was performed in 5 replicates at a constant air temperature of $18^{\circ} \mathrm{C}$ (average air temperature during the growing season in St. Petersburg area).

After the emergence of sprouting, at the stage of the second leaf, 5 healthy plants of the same height and size were left in each pot. The initial moisture content in the vessels was maintained during the experiment. When the plants reached the boot stage, they were taken out of the vessel and cleaned from sand. The roots were separated from the sprouts and weighed to find out the wet mass of the roots and the sprouts. Then the plant material was fixed in the Binder drying 
and heating chamber FD115 (Germany) at a temperature of $120^{\circ} \mathrm{C}$ for 10 minutes to stop the activity of enzymes (fermentation) and after that was dried at a temperature of $60^{\circ} \mathrm{C}$. The wet and dry mass of the roots and the sprouts was measured.

\section{Statistical analyses}

Statistical analyses were performed using R 3.1.2 (R Development Core Team, 2013). One-factorial ANOVA $(p<0.05)$ was used to assess the sorption capacity of biochar and its influence on barley growth and plants' nutrient uptake.

\section{Results and Discussion}

\section{Characteristics of biochar}

The main characteristics of the biochar are presented in Table 3. The biochar studied in the experiment is an alkaline product and that is common for biochars produced at high temperatures. The alkaline nature of biochar makes it a good ameliorant with liming properties for application to acidic soils (Berek et al., 2018). The investigated biochar has high porosity which is supposed to contribute to nutrient adsorption from the solution by capillary forces. High porosity of biochars determines their effect on soil properties, such as water-holding capacity, aeration, bulk density, nutrient leaching, etc.

Elemental composition analysis showed that biochar is a carbon rich material. However, biochar is a stable carbonaceous material and only little part of this carbon is in the labile form available for soil microorganisms and plants. Labile carbon in biochar represents a small proportion of the total content, less than 0.01-0.07 \% (Lin et al., 2012; Uchimiya et al., 2013), and its content and composition are dependent on both the biochar feedstock material and biochar pyrolysis conditions. Biochar has a low concentration of the main macronutrients: ammonium and phosphorus. Therefore, the use of biochar as a fertiliser is not enough to support the plant growth. However, a sufficient amount of basic elements such as calcium, potassium and magnesium in biochar can contribute to the plant growth.
Table 3. Properties and elemental composition of biochar

\begin{tabular}{|c|c|}
\hline Parameter & Value \\
\hline C, \% & 87.4 \\
\hline $\mathrm{N}, \%$ & 0.4 \\
\hline $\mathrm{H}, \%$ & 2.8 \\
\hline $\mathrm{N}-\mathrm{NO}_{3}, \mathrm{mg} \mathrm{kg}^{-1}$ & 1.2 \\
\hline $\mathrm{N}-\mathrm{NH}_{4}, \mathrm{mg} \mathrm{kg}^{-1}$ & 7.3 \\
\hline $\mathrm{P}, \mathrm{mg} \mathrm{kg}^{-1}$ & 10.7 \\
\hline $\mathrm{K}, \mathrm{mg} \mathrm{kg}^{-1}$ & 74 \\
\hline Ca, $\mathrm{mg} \mathrm{kg}^{-1}$ & 3655 \\
\hline $\mathrm{Mg}, \mathrm{mg} \mathrm{kg}^{-1}$ & 958 \\
\hline Fe, $\mathrm{mg} \mathrm{kg}^{-1}$ & 50 \\
\hline $\mathrm{Hg}, \mathrm{mg} \mathrm{kg}^{-1}$ & 0.049 \\
\hline As, $\mathrm{mg} \mathrm{kg}^{-1}$ & 2.6 \\
\hline $\mathrm{Cd}, \mathrm{mg} \mathrm{kg}^{-1}$ & 0.59 \\
\hline $\mathrm{Cu}, \mathrm{mg} \mathrm{kg}^{-1}$ & 16.8 \\
\hline $\mathrm{Ni}, \mathrm{mg} \mathrm{kg}^{-1}$ & 12.9 \\
\hline $\mathrm{Pb}, \mathrm{mg} \mathrm{kg}^{-1}$ & $<0.1$ \\
\hline $\mathrm{Zn}, \mathrm{mg} \mathrm{kg}^{-1}$ & 116.4 \\
\hline Benzopyrene, mg kg-1 & $<0.005$ \\
\hline $\mathrm{pH}$ & 8.34 \\
\hline Porosity, \% & 81 \\
\hline
\end{tabular}

Biochar was analysed for concentrations of heavy metals and benzopyrene to determine the presence of harmful elements in the material. The results of the analysis did not show critical concentrations of these substances in the studied biochar with an exception of zinc.

\section{Nutrient sorption capacity of biochar}

After two weeks of the sorption experiment, BC and EB biochars were analysed for concentrations of nutrients (Table 4). Biochar saturated with distilled water did not lose a significant amount of nutrients during the experiment. Concentrations of nitrate, calcium and magnesium in $\mathrm{BC}$ biochar did not change. Cations $\mathrm{Ca}$ and $\mathrm{Mg}$ are divalent $\left(2^{+}\right)$and can act as an ionic "glue" with negatively charged biochar particles (electrostatic attraction) (Droge and Goss, 2012). At the same time, BC biochar released $18 \%$ of its 
ammonium, $6 \%$ of phosphorus and $5 \%$ of potassium to the water $(p>0.05)$. The reason for that could be the increase of the water $\mathrm{pH}$ due to biochar alkaline nature, which promoted some leaching of the cations $\left(\mathrm{NH}_{4}{ }^{+}, \mathrm{P}_{3}{ }^{+}\right.$and $\left.\mathrm{K}^{+}\right)$, while nitrate leaching could be suppressed. Therefore, it can be concluded that macronutrients in biochar cannot easily be dissolved by water. However, their insignificant amount can be dissolved and then used by plants.

Table 4. Amounts of nutrients in biochar after the saturation experiment

\begin{tabular}{c|c|c|c|c}
\hline Substance & $\begin{array}{c}\mathrm{BC}, \mathrm{mg} \\
\mathrm{kg}^{-1}\end{array}$ & $\mathrm{~EB}, \mathrm{mg} \mathrm{kg}$ & $\begin{array}{c}\text { Adsorbed } \\
\text { nutrients, } \\
\mathrm{mg} \mathrm{kg}^{-1}\end{array}$ & $\begin{array}{c}\text { Coefficient } \\
\text { of sorption } \\
\text { intensity }\end{array}$ \\
\hline $\mathrm{NO}_{3}^{-}$ & $1.2 \pm 0.1$ & $1.2 \pm 0.2$ & 0 & 0 \\
\hline $\mathrm{NH}_{4}^{+}$ & $6 \pm 1.3$ & $114 \pm 11.2$ & 108 & 0.1 \\
\hline $\mathrm{P}$ & $10 \pm 0.1$ & $35 \pm 4.5$ & 25 & 0.8 \\
\hline $\mathrm{K}$ & $71 \pm 4.3$ & $274 \pm 27.6$ & 200 & 5.09 \\
\hline $\mathrm{Ca}$ & $3,650 \pm 10$ & $4,120 \pm 89$ & 470 & 2.4 \\
\hline $\mathrm{Mg}$ & $954 \pm 60$ & $1,000 \pm 68$ & 46 & 1.9 \\
\hline
\end{tabular}

The biochar saturated with the solution (EB) had a significantly $(p<0.05)$ higher concentration of the nutrients, excluding nitrate and magnesium than the biochar saturated with bidistilled water.

Biochar showed the ability to adsorb a significant amount of ammonium. Its concentration increased 18 times by the end of the experiment whereas the concentration of nitrates did not change. The concentration of phosphorus in EB biochar increased 3.5 times with the coefficient of sorption intensity being 0.8. Similar results for $\mathrm{NO}_{3}^{-}, \mathrm{NH}_{4}^{+}$and $\mathrm{PO}_{4}{ }^{3+}$ sorption by biochar were found in the experiment of Yao et al. (2012). They investigated biochars produced from different feedstock and at different temperatures (300$650^{\circ} \mathrm{C}$ ). Little or no nitrate and phosphate sorption ability but significant ammonium removal was found.

Earlier studies pointed out that the ability of biochar to adsorb $\mathrm{NO}_{3}{ }^{-}$and $\mathrm{NH}_{4}{ }^{+}$is highly dependent on the biochar production temperature (Yao et al., 2011; Mizuta et al., 2004). Based on earlier studies, Clough et al. (2013) determined pyrolysis temperature of $600^{\circ} \mathrm{C}$ as a minimum for biochar to have $\mathrm{NO}_{3}^{-}$adsorption potential. Nitrate adsorption could be a result of base functional groups with content higher in biochars produced at high pyrolysis temperatures (due to a high pH value caused by an increase in ash content) (Banno et al., 2009; Kameyama et al., 2012). Conversely, biochar produced at lower temperatures could have a higher ammonium sorption capacity (Zheng et al., 2013). The biochar studied in this experiment was produced at $550^{\circ} \mathrm{C}$ and it could be the reason for no $\mathrm{NO}_{3} \mathrm{~N}$ and considerably high $\mathrm{NH}_{4}-\mathrm{N}$ sorption. Besides, the temperature of biochar production could be the reason of low $\mathrm{NO}_{3}{ }^{-}$anion sorption. Cheng et al. (2008) after 12 months of biochar incubation found disappearance of surface positive charge and an increase of surface negative charge due to the oxidation process.

The influence of the chemical composition of biochar on the $\mathrm{PO}_{4} \mathrm{P}$ sorption capacity was found in some experiments (Takaya et al., 2016; Wang et al., 2015). Yao et al. (2012) and Zheng et al. (2013) noticed in their experiments that biochar with a high $\mathrm{Mg}$ content (above $3 \mathrm{~g} \mathrm{~kg}^{-1}$ ) could have a sufficient $\mathrm{PO}_{4}-\mathrm{P}$ sorption capacity. Probably, a low Mg content in the investigated biochar $\left(0.96 \mathrm{~g} \mathrm{~kg}^{-1}\right)$ caused such a little sorption intensity of $\mathrm{PO}_{4}-\mathrm{P}$ by biochar.

EB biochar also had a high sorption intensity to potassium, calcium and magnesium. It adsorbed a significant $(p<0.05)$ amount of potassium and calcium and not a significant $(p>0.05)$ amount of magnesium. Their concentration increased 3.9, 1.1 and 1.04 times for K, Ca and Mg, respectively. A high sorption intensity of these nutrients by biochar can be related to negatively charged particles on the char surface, which increase in aged biochars. A low sorption intensity of $\mathrm{Mg}$ by the studied biochar could be partly attributed to the increased Ca concentration, the adsorption of which would be favoured onto the substrate exchange sites compared with Mg (Jalali and Ranjbar, 2009). Low Mg concentrations are considered to be good with respect to the soil structure, as some studies have shown that elevated soluble or exchangeable $\mathrm{Mg}^{2+}$ could be deleterious in maintaining the soil permeability (Mahmoodabadi et al., 2013). The studied biochar was produced one year before the experiment and probably had a high amount of negatively charged functional groups on its surface. It could facilitate the attraction of cations to the biochar surface. 
A high sorption capacity of biochar resulted in its enrichment with nutrients and that can have an effect on plant growth.

\section{Nutrients uptake from biochar}

In the $\mathrm{BC}$ treatment, the deficiency in the main macronutrients such as N, P and $\mathrm{K}$ and a significant amount of $\mathrm{Ca}$ and $\mathrm{Mg}$ introduced to the sand with biochar were observed, which could contribute to the pool of plant available nutrients upon incorporation to the soil (Table 5).

Table 5. Amounts of nutrients inserted to the vessels ( $B C$ and $E B$ ) and adsorbed by biochar

\begin{tabular}{c|c|c|c}
\hline \multicolumn{1}{c|}{ Element } & BC & EB & $\begin{array}{c}\text { Nutrients } \\
\text { adsorbed by } \\
\text { biochar }\end{array}$ \\
\hline $\mathrm{N}, \mathrm{mg} \mathrm{vessel}^{-1}$ & $0.9 \pm 0.06$ & $18.2 \pm 1.27$ & $17.3 \pm 1.21$ \\
\hline $\mathrm{P}, \mathrm{mg} \mathrm{vessel}^{-1}$ & $1.6 \pm 0.11$ & $5.6 \pm 0.39$ & $4.0 \pm 0.28$ \\
\hline $\mathrm{K}, \mathrm{mg} \mathrm{vessel}^{-1}$ & $11.8 \pm 0.81$ & $43.8 \pm 3.04$ & $32.0 \pm 2.22$ \\
\hline Ca, mg vessel $^{-1}$ & $584.0 \pm 40.86$ & $659.2 \pm 46.12$ & $75.2 \pm 5.31$ \\
\hline $\mathrm{Mg}, \mathrm{mg}$ vessel $^{-1}$ & $153.0 \pm 10.41$ & $160.4 \pm 11.45$ & $7.4 \pm 0.55$ \\
\hline
\end{tabular}

When biochar was saturated with the nutrient solution (EB treatment), the amount of nutrients in biochar increased significantly, except for the amount of magnesium.

The results showed that the $\mathrm{BC}$ biochar was capable of supporting plant biomass production (Fig. 2). Dry biomass of barley plants in $\mathrm{BC}$ treatment reached 1.4 $\mathrm{g}$ vessel ${ }^{-1}$. It can be concluded that some nutrients from biochar were available for plants. Based on the results of the sorption experiment, part of ammonia, phosphorus and potassium from biochar could be dissolved by water and subsequently used by plants.

Nutrients adsorbed by biochar had a positive effect on the plant biomass growth. Barley dry biomass was $46 \%$ higher in EB treatment in comparison with BC treatment. Similar results with nutrient enriched biochars were found in some experiments (Kamman et al., 2015; Brantley et al., 2015; Schmidt et al., 2015). Brantley et al. (2015) in their study with pine woodchip biochar found a significant increase of corn yield when biochar was applied together with a nitrogen
Fig. 2. Dry biomass production of barley plants at the end of the experiment

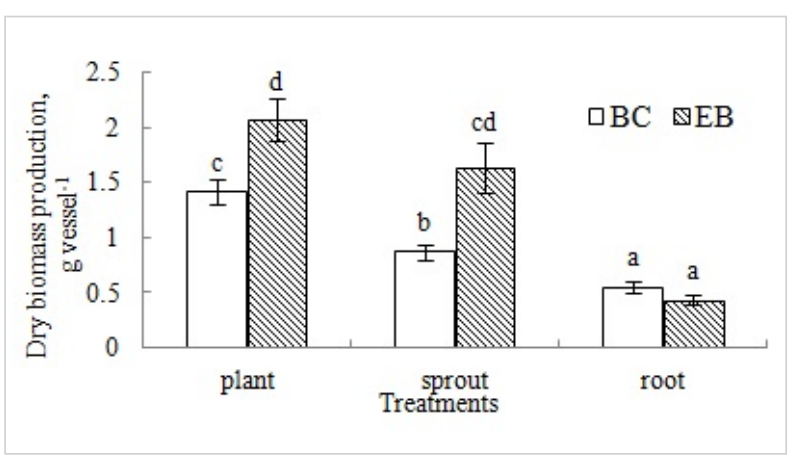

fertiliser while biochar alone caused a significant yield decrease in comparison with no biochar treatment. Biochar enriched with mineral nitrogen $\left(\mathrm{NH}_{4}^{+}\right.$and $\mathrm{NO}_{3}{ }^{-}$) and phosphate could work as a fertiliser slowly providing nutrients and, thus, improving plant growth (Kammann et al., 2015; Schmidt et al., 2015).

Dry biomass of barley sprouts in EB treatment was significantly $(p<0.05)$ higher than in BC treatment. The difference reached $90 \%$. Release of the nutrients adsorbed by biochar could be the reason of a higher dry biomass yield in EB treatment. For example, Liu et al. (2019) in their experiment with urea-enriched biochar found a $61-98 \%$ release of nitrogen from biochar to the soil through dissolution and diffusion processes.

The influence of biochar on the root growth and the allocation of resources to roots could be a major factor to emphasise nutrient acquisition and, consequently, higher plant growth. Dry biomass of the roots in EB treatment was insignificantly lower than in BC treatment. This can be explained by the physiology of root systems growth, which is dependent on nutrient content. In poor substrates, root growth is more intensive as they search for nutrients. With an optimal soil nutrient composition, the main function of roots is to transport nutrients to sprouts, so the roots form smaller biomass.

\section{Concentration and removal of nutrients by plants}

Biochar can increase plant nutrient uptake serving as a source of nutrients and improving the sorption of nutrients from soil (Lehmann et al., 2003). Since biochars are produced from organic materials, they 
inherently contain nutrients that are found in minerals. Therefore, the addition of biochar to soil adds free exchangeable bases such as $\mathrm{K}, \mathrm{Ca}$, and $\mathrm{Mg}$ to occupy soil-exchange sites, thus resulting in an increase in nutrients supplying plant growth (Glaser et al., 2002). Sandy textured soils also give biochar the potential to ameliorate P leaching in soils (Gronwald et al., 2015); therefore, $\mathrm{P}$ content should increase with increasing levels of biochar additions (Novak et al., 2009).

Concentrations of nutrients in sprouts and roots of barley plants varied between the treatments (Table 6). $\mathrm{N}$ and $\mathrm{K}$ concentrations in barley roots were significantly higher $(p<0.05)$ in $E B$ than in $B C$; while concentrations of $\mathrm{Ca}$ and $\mathrm{Mg}$ in EB were lower $(p<0.05)$ than in $\mathrm{BC}$ treatment. The concentration of $P$ between these treatments was without a significant difference. Barley sprouts in EB treatment showed significantly lower $(p<0.05)$ concentrations of $\mathrm{N}, \mathrm{P}, \mathrm{K}$ and $\mathrm{Ca}$ than in $\mathrm{BC}$ treatment.
Concentrations of $\mathrm{N}$ and $\mathrm{K}$ in barley plants were without a significant difference between the treatments (Table 6). However, concentrations of $\mathrm{Ca}$ and $\mathrm{Mg}$ in $\mathrm{BC}$ treatment were significantly $(p<0.05)$ higher than in EB treatment (1.6 and 1.4 times higher, respectively). Probably, lower concentrations of nutrients in plants in this treatment in comparison with $\mathrm{BC}$ are connected with higher dry biomass yields of barley in EB treatment and dilution of the nutrients' contents in the plants. Another hypothesis is that nutrients from EB treatment could have a short-term effect due to a flush release of nutrients.

Probably, lower concentrations of nutrients in plants in $\mathrm{EB}$ treatment in comparison with $\mathrm{BC}$ treatment are connected with higher yields of barley in EB treatment and dilution of nutrients' content in the plants. The total nutrient content in barley plants was compared to test this hypothesis (Table 7).

Table 6. Concentration of nutrients in barley

\begin{tabular}{c|c|c|c|c|c|c|c}
\multicolumn{2}{c|}{ Treatment } & N, \% & P, \% & K, \% & Ca, \% & Mg, \% \\
\hline \multirow{3}{*}{ Plant } & BC & $1.75 c$ & $0.74 c$ & $4.99 \mathrm{e}$ & $12.52 \mathrm{e}$ & $6.14 \mathrm{~d}$ \\
\cline { 2 - 8 } & EB & $1.77 \mathrm{c}$ & $0.45 \mathrm{ab}$ & $4.93 \mathrm{e}$ & $7.75 \mathrm{~cd}$ & $4.32 \mathrm{bc}$ \\
\hline \multirow{3}{*}{ Sprouts } & BC & $1.25 \mathrm{~b}$ & $0.57 \mathrm{~b}$ & $4.41 \mathrm{~d}$ & $6.03 \mathrm{c}$ & $2.39 \mathrm{ab}$ \\
\cline { 2 - 8 } & EB & $1.15 \mathrm{~b}$ & $0.29 \mathrm{ab}$ & $4.23 \mathrm{c}$ & $4.83 \mathrm{~b}$ & $2.43 \mathrm{ab}$ \\
\hline \multirow{2}{*}{ Roots } & BC & $0.50 \mathrm{a}$ & $0.17 \mathrm{a}$ & $0.59 \mathrm{a}$ & $6.49 \mathrm{c}$ & $3.75 \mathrm{~b}$ \\
\cline { 2 - 8 } & EB & $0.622 \mathrm{a}$ & $0.16 \mathrm{a}$ & $0.73 \mathrm{~b}$ & $2.92 \mathrm{a}$ & $1.89 \mathrm{a}$ \\
\hline
\end{tabular}

Data are means of $n=5$. Different letters in the same column indicate significant differences between the treatments. ( $p<0.05)($ ANOVA)

Table 7. The total content of nutrients in barley plants

\begin{tabular}{|c|c|c|c|c|c|c|}
\hline \multicolumn{2}{|c|}{ Treatment } & $\mathrm{N}, \mathrm{mg}$ & $\mathrm{P}, \mathrm{mg}$ & $\mathrm{K}, \mathrm{mg}$ & $\mathrm{Ca}, \mathrm{mg}$ & $\mathrm{Mg}, \mathrm{mg}$ \\
\hline \multirow{2}{*}{ Sprouts } & $\mathrm{BC}$ & $10.88 \pm 0.85 c$ & $4.96 \pm 0.40 c$ & $38.37 \pm 2.51 c$ & $52.46 \pm 4.40 c$ & $20.79 \pm 1.63 c$ \\
\hline & EB & $18.86 \pm 2.67 e$ & $4.76 \pm 0.68 c$ & $69.37 \pm 9.81 d$ & $79.21 \pm 11.3 d$ & $39.85 \pm 5.57 d$ \\
\hline \multirow{2}{*}{ Roots } & $\mathrm{BC}$ & $2.15 \pm 0.3 a$ & $0.73 \pm 0.076 a$ & $2.54 \pm 0.25 a$ & $27.91 \pm 2.91 b$ & $16.13 \pm 2.17 b$ \\
\hline & EB & $3.42 \pm 0.29 b$ & $0.88 \pm 0.070 b$ & $4.02 \pm 0.32 b$ & $16.06 \pm 1.35 a$ & $10.40 \pm 0.84 a$ \\
\hline \multirow{2}{*}{ Plants } & $\mathrm{BC}$ & $13.03 \pm 1.15 d$ & $5.69 \pm 0.47 d$ & $40.91 \pm 2.76 c$ & $80.37 \pm 7.31 d$ & $36.92 \pm 3.8 d$ \\
\hline & EB & $22.28 \pm 2.96 \mathrm{e}$ & $5.64 \pm 0.75 d$ & $73.39 \pm 10.13 d$ & $95.27 \pm 12.65 d$ & $50.25 \pm 6.41 \mathrm{e}$ \\
\hline
\end{tabular}

Data are means of $n=5$. Different letters in the same column indicate significant differences between the treatments. $(p<0.05)($ ANOVA) 
$\mathrm{N}, \mathrm{K}$ and $\mathrm{Mg}$ contents in barley plants were significantly higher in EB treatment than in BC treatment, while there was no significant difference in $\mathrm{P}$ and $\mathrm{Ca}$ contents between these treatments. These results confirm the hypothesis of nutrient dilution in barley plants in EB.

Nutrient-enriched biochar (EB) increased the nitrogen content in barley plants up to $71 \%$, the potassium content up to $79 \%$ and the magnesium content up to $36 \%$ in comparison with BC treatment. Similar results were found in a study of Morandi et al. (2019). In their experiment with biochar enriched by rock phosphate and cow manure, an increase in N, P and $\mathrm{K}$ in saline soil was observed. In an experiment of Kizito et al. (2019), digestate-enriched biochar improved maize growth and increased the content of soil organic matter and macronutrients in clay loam soil. The relationship between dry matter and nutrient content in barley plants suggested that biochar enriched with nutrients could slowly release them and provide to the plants, thus improving their growth.

\section{Conclusions}

It was demonstrated that the biochar made of wood had high porosity and sorption capacity. It adsorbed such cations as ammonium, calcium, phosphorus and potassium. The biochar saturated with the Gelrigel solution showed the ability to adsorb a significant $(p<0.05)$ amount of ammonium, phosphorus and potassium by $18,3.5$ and 3.9 times higher, respectively, compared with control. The sorption capacity of biochar can be an option for nutrient leaching mitigation. However, there is a need in further investigations of
$\mathrm{N}$ and $\mathrm{P}$ content in roots and sprouts of barley under $B C$ and $E B$ treatments were not significantly different $(p>0.05)$. The concentration of $K$ in barley roots in EB treatment increased by $24 \%(p<0.05)$ under the influence of potassium adsorbed by biochar from the nutrient solution. Conversely, the concentration of $\mathrm{K}$ in barley sprouts in $\mathrm{EB}$ treatment was $4 \%$ lower $(p<0.05)$ than in BC treatment. The lower concentration of potassium in EB barley sprouts can be connected with significantly higher dry biomass of $E B$ sprouts in comparison with BC and dilution of this element in sprouts. Some experiments showed an increase in $\mathrm{K}$ uptake by plants after biochar application and availability of $\mathrm{K}$ from biochar to plants (Lehmann et al., 2003; Chan et el., 2008). However, Widowati and Asnah (2014) in their experiment noticed a decrease in the potassium uptake for the treatment of joint application of biochar with a $\mathrm{K}$ fertiliser compared with the treatment with a $\mathrm{K}$ fertiliser only while yields in biochar treatments were higher. factors which influence biochar sorption capacity and its effect on nutrient leaching.

The current results indicate that a single $\mathrm{BC}$ application of $25 \mathrm{tha}^{-1} \mathrm{can}$ also increase plant biomass at least over the first cropping season. But the nutrient-enriched biochar showed the ability to support significantly $(p<0.05)$ higher dry biomass of barley plants, which was by $46 \%$ higher of what was achieved using non-enriched biochar. Further research will be important to validate these results for soils in field experiments.

\section{Acknowledgements}

Most of the work was supported by the Ministry of Science and High Education and was conducted at the Agrophysical Research Institute as part of the government assignment.

We thank Dr. N. Buchkina for reviewing the paper. 


\section{References}

Arinushkina, E. V. (1970) Chemical analysis manual. MSU, Moscow.

ASTM D854-14, Standard Test Methods for Specific Gravity of Soil Solids by Water Pycnometer, ASTM International, West Conshohocken, PA, 2014, www.astm.org.

Banno M., Kuba T., Sano K., et al. (2009) Capacity and mechanism of nitrate anion adsorption onto bamboo charcoal. Journal of Japan Society on Water Environment 32: 369-374. https://doi.org/10.2965/jswe.32.369

Berek A. K., Hue N. V., Radovich T. J. K. and Ahmad A. A. (2018) Biochars improve nutrient phyto-availability of $\mathrm{Ha}$ wai'i's highly weathered soils. Agronomy 8 (10): 203. https:// doi.org/10.3390/agronomy8100203

Biederman L. A. and Harpole W. S. (2013) Biochar and its effects on plant productivity and nutrient cycling: a meta-analysis. Global Change Biology Bioenergy 5: 202-2014. https://doi. org/10.1111/gcbb.12037

Bonanomi G., Ippolito F., Cesarano G., Nanni B., Lombardi M., Rita A., Saracino A. and Scala C. (2017) Biochar as plant growth promoter: Better off alone or mixed with organic amendments? Frontiers in Plant Science 8: 1570. https://doi. org/10.3389/fpls.2017.01570

Brantley K. E., Savin M., Brye K. R. and Longer D. E. (2015) Pine woodchip biochar impact on soil nutrient concentrations and corn yield in a silt loam in the Mid-Southern U.S. Agriculture 5: 30-47. https://doi.org/10.3390/agriculture5010030

Clough T. J., Condron L. M., Kammann C. and Muller C. (2013) A Review of Biochar and Soil Nitrogen Dynamics, Agronomy 3:275-293. https://doi.org/10.3390/agronomy3020275

Cornelissen G., Martinsen V., Shitumbanuma V., Alling V., Breedveld G. D., Rutherford D. W., Sparrevik M., Hale S. E., Obia A. and Mulder J. Biochar effect on maize yield and soil characteristics in five conservation farming sites in Zambia. Agronomy 3: 256-274. https://doi.org/10.3390/agronomy3020256

Downie A., Crosky A. and Munroe P. (2009) Physical Properties of Biochar. In: Biochar for Environmental Management: Science and Technology, J. Lehmann, S. Joseph (Eds.). Earthscan, London.https://www.taylorfrancis.com/books/e/9781849770552/ chapters/10.4324/9781849770552-9.

Droge S. and Goss K. U. (2012) Effect of sodium and calcium cations on the ion-exchange affinity of organic cations for soil organic matter. Environmental science \& technology 46 (11): 5894-5901. https://doi.org/10.1021/es204449r

Fujita I., Tomooka J. and Sugimura T. (1991) Sorption of anionic surfactants with wood charcoal. Bulletin of the Chem- ical Society of Japan 64: 738-740. https://doi.org/10.1246/ bcsj.64.738

Glaser B., Lehmann J. and Zech W. (2002) Ameliorating physical and chemical properties of highly weathered soils in the Tropics with charcoal - a review. Biology and Fertility of Soils 35: 219-230. https://doi.org/10.1007/s00374-002-0466-4

Gronwald M., Don A., Tiemeyer B., et al. (2015) Effects of fresh and aged chars from pyrolysis and hydrothermal carbonization on nutrient sorption in agricultural soils. Soil 1: 475-489. https://doi.org/10.5194/soil-1-475-2015

Jalali M. and Ranjbar F. (2009) Rates of Decomposition and Phosphorus Release from Organic Residues Related to Residue Composition. Journal of Plant Nutrition and Soil Science 172: 353-359. https://doi.org/10.1002/jpln.200800032

Jeffery S., Verheijen F. G. A., van der Velde M., et al. (2011) A quantitative review of the effects of biochar application to soils on crop productivity using meta-analysis. Agriculture, Ecosystems and Environment 144: 175-187. https://doi. org/10.1016/j.agee.2011.08.015

Kameyama K., Miyamoto T., Shiono T. and Shinogi Y. (2012) Influence of sugarcane bagasse-derived biochar application on nitrate leaching in calcaric dark red soil. Journal of Environmental Quality 41: 1131-1137. https://doi.org/10.2134/jeq2010.0453 Kammann C. I., Schmidt H. P., Messerschmidt N., Linsel S., Steffens D., Muller C., Koyro H. W., Conte P. and Joseph S. (2015) Plant growth improvement mediated by nitrate capture in co-composted biochar. Scientific Reports 5: 11080. https:// doi.org/10.1038/srep11080

Kinney T. J., Masiello C. A., Dugan B., Hockaday W. C., Dean M. R., Zygourakis K. and Barnes R. T. (2012) Hydrologic properties of biochars produced at different temperatures. Biomass \& Bioenergy 41: 34-43. https://doi.org/10.1016/j.biombioe.2012.01.033

Laird D. A., Fleming P., Wang B. Q., et al. (2010) Biochar impact on nutrient leaching from a Midwestern agricultural soil. Geoderma 158: 436-442. https://doi.org/10.1016/j.geoderma.2010.05.012

Lehmann J. (2007) A handful of carbon. Nature 447: 143-144. https://doi.org/10.1038/447143a

Lehmann J., Pereira da Silva Jr. J., Steiner C., Nehls T., Zech W. and Glaser B. (2003) Nutrient availability and leaching in an archaeological Anthrosol and a Ferralsol of the Central Amazon basin: fertilizer, manure and charcoal amendments. Plant and Soil 249: 343-357. https://doi.org/10.1023/A:1022833116184

Liu X., Liao J., Song H., Yang Y., Guan C. and Zhang Z. (2019) A Biochar-Based Route for Environmentally Friendly Controlled 
Release of Nitrogen: Urea-Loaded Biochar and Bentonite Composite. Scientific Reports 9: 9548. https://doi.org/10.1038/ s41598-019-46065-3

Lin Y., Munroe P., Joseph S., Henderson R., and Ziolkowski A. (2012) Water extractable organic carbon in untreated and chemical treated biochars. Chemosphere 87: 151-157. https:// doi.org/10.1016/j.chemosphere.2011.12.007

Mahmoodabadi M., Yazdanpanah N., Sinobas L. R., Pazira E. and Neshat A. (2013) Reclamation of calcareous saline sodic soil with different amendments (I): redistribution of soluble cations within the soil profile. Agricultural Water Management 120: 30-38. https://doi.org/10.1016/j.agwat.2012.08.018

Major J., Rondon M. and Molina D. (2010) Maize yield and nutrition during 4 years after biochar application to a Colombian savanna oxisol. Plant and Soil 333:117-128. https://doi. org/10.1007/s11104-010-0327-0

Mizuta K., Matsumoto T., Hatate Y., et al. (2004) Removal of nitrate-nitrogen from drinking water using bamboo powder charcoal. Bioresource Technology 95: 255-257 https://doi. org/10.1016/j.biortech.2004.02.015

Moreno-Castilla C. (2004) Adsorption of organic molecules from aqueous solutions on carbon materials. Carbon 42: 8394.https://doi.org/10.1016/j.carbon.2003.09.022

Novak J. M., Busscher W. J., Laird D. L., Ahmedna M., Watts D. W. and Niandou M. A. S. (2009) Impact of biochar amendment on fertility of a southeastern Coastal Plain soil. Soil Science 174: 105-112. https://doi.org/10.1097/SS.0b013e3181981d9a

Patra D. D., Muni R. and Singh D. V. (1993) Influence of straw mulching on fertilizer nitrogen use efficiency, moisture conservation and herb and essential oil yield in Japanese mint (Mentha arvensis L.). Nutr. Cycl. Agroecosys. 34: 135-139. https://doi.org/10.1007/BF00750108

Prusakova L. D., Kefeli V. I., Belopukhov S. L., Vakulenko V. V. and Kuznetsova S. A. (2008) The role of phenolic compounds in plants. Agrochimiya [Agricultural Chemistry]. 7: 86-97. (in Russian).

Sander M. and Pignatello J. J. (2005) Characterization of charcoal adsorption sites for aromatic compounds: insights drawn from single-solute and bi-solute competitive experiments. Environmental Science \& Technology 39: 1606-1615. https://doi. org/10.1021/es049135l

Savci S. (2012) An Agricultural Pollutant: Chemical Fertilizer. International Journal of Environmental Science and Development 3: 77-80. https://doi.org/10.7763/IJESD.2012.V3.191

Shepherd J. G., Sohi S. P. and Heal K. V. (2016) Optimising the recovery and re-use of phosphorus from wastewater effluent for sustainable fertilizer development. Water Research 1(94): 155-165. https://doi.org/10.1016/j.watres.2016.02.038

Schmidt H., Pandit B., Martinsen V., et al. (2015) Fourfold increase in pumpkin yield in response to low-dosage root zone application of urine-enhanced biochar to a fertile tropical soil. Agriculture 5: 723-741. https://doi.org/10.3390/agriculture5030723

Spokas K. A., Cantrell K. B., Novak J. M., et al. (2012) Biochar: a synthesis of its agronomic impact beyond carbon sequestration. Journal of Environmental Quality 41: 973-989. https:// doi.org/10.2134/jeq2011.0069

Takaya C. A., Fletcher L. A., Singh S., et al. (2016) Phosphate and ammonium sorption capacity of biochar and hydrochar from different wastes. Chemosphere 145: 518-527. https://doi. org/10.1016/j.chemosphere.2015.11.052

Uchimiya M., Tsutomu O. and Zhongqi H. (2013) Pyrolysis temperature-dependent release of dissolved organic carbon from plant, manure, and biorefinery wastes. Journal of Analytical and Applied Pyrolysis 104: 84-94. https://doi.org/10.1016/j. jaap.2013.09.003

Van Zwieten L. (2009) Biochar and emissions of non-CO2 greenhouse gases from soil. Biochar for environmental management: science and technology. Lehmann, S. Joseph (Eds.). Routledge, London.

Wang S., Gao B., Zimmerman A.R., et al. (2015) Physicochemical and sorptive properties of biochars derived from woody and herbaceous biomass. Chemosphere 134: 257-262. https://doi. org/10.1016/j.chemosphere.2015.04.062

Widowati W. and Asnah A. (2014) Biochar can enhance potassium fertilization efficiency and economic feasinility of maize cultivation. Journal of Agricultural Science 6(2): 24-32. https:// doi.org/10.5539/jas.v6n2p24

Yao Y., Gao B., Zhang M., et al. (2012). Effect of biochar amendment on sorption and leaching of nitrate, ammonium, and phosphate in a sandy soil. Chemosphere 89: 1467-1471. https://doi.org/10.1016/j.chemosphere.2012.06.002

Zhang H., Voroney R. and Price G. (2015) Effects of temperature and processing conditions on biochar chemical properties and their influence on soil $\mathrm{C}$ and $\mathrm{N}$ transformations. Soil Biology \& Biochemistry 83: 19-28. https://doi.org/10.1016/j. soilbio.2015.01.006

Zheng H., Wang Z., Deng X., et al. (2013) Characteristics and nutrient values of biochars produced from giant reed at different temperatures. Bioresource Technology 130: 463-471. https://doi.org/10.1016/j.biortech.2012.12.044 